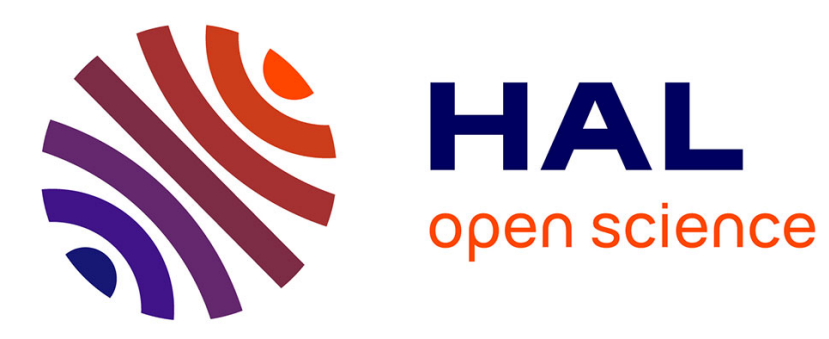

\title{
Sildenafil for the treatment of preeclampsia, an update: should we still be enthusiastic?
}

Noémie Simon-Tillaux, Edouard Lecarpentier, Vassilis Tsatsaris, Alexandre Hertig

\section{- To cite this version:}

Noémie Simon-Tillaux, Edouard Lecarpentier, Vassilis Tsatsaris, Alexandre Hertig. Sildenafil for the treatment of preeclampsia, an update: should we still be enthusiastic?. Nephrology Dialysis Transplantation, In press, 10.1093/ndt/gfy328 . hal-02022768

\section{HAL Id: hal-02022768 https://hal.sorbonne-universite.fr/hal-02022768}

Submitted on 18 Feb 2019

HAL is a multi-disciplinary open access archive for the deposit and dissemination of scientific research documents, whether they are published or not. The documents may come from teaching and research institutions in France or abroad, or from public or private research centers.
L'archive ouverte pluridisciplinaire HAL, est destinée au dépôt et à la diffusion de documents scientifiques de niveau recherche, publiés ou non, émanant des établissements d'enseignement et de recherche français ou étrangers, des laboratoires publics ou privés. 


\title{
Sildenafil for the treatment of preeclampsia, an update: should we still be enthusiastic?
}

\author{
Noémie Simon-Tillaux ${ }^{1}$, Edouard Lecarpentier ${ }^{2}$, Vassilis Tsatsaris ${ }^{3,4}$ and Alexandre Hertig ${ }^{1,5}$ \\ ${ }^{1}$ Department of Nephrology and Kidney Transplantation, Hôpital Tenon, Assistance publique - Hôpitaux de Paris, Paris, France, ${ }^{2}$ Department \\ of Obstetrics and Gynecology and Reproductive Medicine, University Paris Est Créteil, Centre Hospitalier Inter-Communal de Créteil, Créteil, \\ France, ${ }^{3}$ Department of Obstetrics and Gynecology, Port-Royal Maternity, Assistance publique - Hôpitaux de Paris, Cochin Hospital, Paris, \\ France, ${ }^{4}$ Paris Descartes University, Paris, France and ${ }^{5}$ Sorbonne Université, UPMC Université Paris 06, UMR_S 1155, Paris, France
}

Correspondence and offprint requests to: Alexandre Hertig; E-mail: alexandre.hertig@sorbonne-universite.fr; Twitter handle: @alexhertig

\begin{abstract}
Preeclampsia is a hypertensive disorder of pregnancy and the clinical manifestation of severe endothelial dysfunction associated with maternal and foetal morbidity and mortality. The primum movens of the disease is the defect of invasion of the uterine arteries by foetal syncytiotrophoblasts, which causes a maladaptive placental response to chronic hypoxia and the secretion of the soluble form of type 1 vascular growth endothelial factor receptor, also called soluble fms-like tyrosine kinase 1 (sFlt-1), the major player in the pathophysiology of the disease. Among its different effects, sFlt-1 induces abnormal sensitivity of the maternal vessels to the vasoconstrictor angiotensin II. This leads to the hypertensive phenotype, recently shown to be abrogated by the administration of sildenafil citrate, which can potentiate the vasodilatory mediator nitrite oxide. This review focuses on the mechanisms of maternal endothelial dysfunction in preeclampsia and discusses the therapeutic window of sildenafil use in the context of preeclampsia, based on the results from preclinical studies and clinical trials. Safety issues recently reported in neonates have considerably narrowed this window.
\end{abstract}

Keywords: angiotensin II, nitric oxide, preeclampsia, sildenafil, sFlt-1

\section{INTRODUCTION}

\section{Preeclampsia: a worldwide syndrome without a cure}

Preeclampsia is a clinical syndrome occurring after 20 weeks of gestation and typically characterized on the maternal side by new-onset hypertension and proteinuria (>300 mg/day) [1] and other maternal organ dysfunctions, such as renal failure, liver microangiopathy, neurological or haematological complications, utero-placental dysfunction or foetal growth restriction. The pathophysiology relies on a defective invasion of uterine arteries by the extravillous cytotrophoblasts (of unknown causes)
[2]. A history of preeclampsia is found in up to $12 \%$ of cases of intrauterine growth retardation (IUGR) and is associated with preterm birth and foetal death, particularly in its early-onset presentation [3]. The health and economic burden associated worldwide with this syndrome are considerable since $2-8 \%$ of pregnant women globally will develop preeclampsia, mostly after 35 weeks of gestational age $[3,4]$. Immediate maternal mortality due to preeclampsia is estimated to be as high as 50000 deaths each year, the majority of which are in low-income countries. Longer term, preeclampsia (especially early-onset preeclampsia and recurring preeclampsia) is also associated with an increased risk of cardiovascular events, including fatal ones [5-9]. Beyond this, preeclampsia also increases the cardiovascular risk profile in the offspring [10], while hypertension, stroke and cognitive impairment are more frequent [11-13]. However, this issue is complex since lifestyle and genes overlap here.

To date, no specific therapeutic intervention has been proven to reduce any of these risks, short or long term and, except for placental delivery, caregivers are left with very few preventive or curative options. Pre- and postpartum hypertension are routinely treated with nonspecific, short-life agents, such as nicardipine, labetalol and alpha-methyldopa.

\section{Endothelial dysfunction in preeclampsia: angiogenic imbalance and angiotensin II sensitivity}

Understanding of the pathophysiology of the maternal syndrome has advanced over the last 15 years. In short, it has been repeatedly demonstrated that a preeclamptic placenta secretes several antiangiogenic factors in excess, which contribute to endothelial dysfunction in the mother [4]. It has long been known that the hallmark of such endothelial dysfunction is the exaggerated arterial response to angiotensin II (AngII), whereas pregnancy is assumed to be a state of relative resistance to vasopressors [2]. 
Among the antiangiogenic factors, soluble fms-like tyrosine kinase 1 (sFlt-1) is central to the maternal phenotype. sFlt-1 is the soluble form of type 1 vascular endothelial growth factor receptor (VEGFR-1) and acts by trapping and neutralizing both vascular endothelial growth factor A (VEGF-A) and placental growth factor (PIGF), two pro-angiogenic growth factors [14]. Its pathogenic role was first demonstrated in a seminal clinical trial in 2003 in a rat model of preeclampsia shortly after the observation by a team of oncologists that bevacizumab, a monoclonal antibody targeting VEGF-A, like sFlt-1, was frequently complicated by a preeclampsia-like syndrome $[15,16]$. Strategies that aim to reduce sFlt1 concentration in maternal blood using (nonspecific) extracorporeal devices have shown conflicting results and are not routinely prescribed at the bedside $[17,18]$.

\section{Sildenafil as a new hope in the search for a cure for preeclampsia}

Recently Burke et al. [19] demonstrated that in the sFlt-1-induced mouse model of preeclampsia, an increased concentration of sFlt-1 was mechanistically involved in abnormal AngII sensitivity and that this abnormal sensitivity could be abrogated by the administration of sildenafil citrate (SC), a phosphodiesterase 5 (PDE5) inhibitor. By diminishing the PDE5-mediated catabolism of cyclic guanosine monophosphate [cGMP; the biological mediator of the potent vasodilator nitric oxide (NO)], SC artificially increases NO-induced vasodilation (Figure 1). This is particularly important in the setting of preeclampsia, where the bioavailability of NO is reduced [22] and is thought to lead to hypertension, platelet aggregation and cellular inflammation.

SC was first developed to treat heart failure, but it eventually became the drug of choice to treat erectile dysfunction and then pulmonary hypertension [23]. Of note, SC has no effect on female sexual dysfunction [24]. Based on the observation that vessels from preeclamptic women have a preserved vasodilatory response to NO, PDE5 inhibitors were actually tested in the setting of preeclampsia as early as 2004 [25]. Since then, promising in vitro and in vivo animal studies have been published, but in the clinical trials testing SC, the outcome of women with preeclampsia was less favourable. In addition, major safety issues regarding neonates have recently been published and were widely reported in the lay press. This review aims to clarify the perspectives afforded by the most recent experimental and clinical studies. We performed a literature search using the PubMed database, with PDE5, sildenafil, preeclampsia, foetal growth retardation and pregnancy as Medical Subject Headings (MeSH) keywords and with no date limitation.

\section{PREECLAMPSIA: FROM PLACENTA DYSFUNCTION TO MATERNAL PATHOLOGICAL ENDOTHELIUM}

In endothelial cells, $\mathrm{NO}$ is a gas produced from L-arginine by endothelial NO synthase (eNOS), and its biological effect on smooth muscle cells is mediated by cGMP (Figure 1). cGMP decreases calcium content that induces relaxation of the vasculature [23]. AngII acts in just the opposite way: the binding of its receptor (ATR1) induces phospholipase C and D (PLC, PLD), which increases intracellular calcium content through lipid messengers, and induces a potent contraction of smooth muscle cells. In preeclampsia, endothelin-1 production by the endothelium in response to AngII fuels the same signalling pathways of AngII in smooth muscle cells through the endothelin receptor type $\mathrm{A}\left(\mathrm{ET}_{\mathrm{A}}\right)$, thus potentializing its vasoconstrictor effect (Figure 2).

AngII is produced from the cleavage of angiotensinogen into angiotensin I (AngI) by renin and then converted into AngII by angiotensin-converting enzyme (ACE). When transgenic mice expressing human angiotensinogen are fertilized with transgenic males expressing human renin (with the consequent placenta also expressing human renin), a preeclamptic phenotype is seen [28]. Although the clinical significance is poorly understood, some preeclamptic women display activating autoantibodies directed against ATR1, which is capable of inducing its heterodimerization with the bradykinin $\beta 2$-receptor and which results in an increased response to AngII (despite lower levels in preeclamptic patients) $[29,30]$. A state of relative vasodilation is another potential mechanism for the loss of resistance to vasopressors, particularly to AngII, observed in preeclampsia compared with normal pregnancy [31]. Interestingly, this abnormal sensitivity to AngII lasts beyond delivery: it is still observed in the skin microvasculature of women with a recent (6 months) history of preeclampsia and is borderline significant for mean arterial pressure 5 years after the event $[32,33]$. Nevertheless, targeting AngII or the use of ACE is not realistic in pregnant women because of associated severe cardiac and renal defects in the offspring $[34,35]$.

Conversely, pregnant women exhibit increased activation of eNOS (through increased phosphorylation); this advantage is lost, however, at the very beginning of preeclampsia $[19,36]$. Increased production by preeclamptic placentas of soluble endoglin (sENG), the soluble form of the endothelial receptor of transforming growth factor beta (TGF- $\beta$ ), is involved in reduced eNOS activity [29]. By trapping TGF- $\beta$ and VEGF, sENG and sFlt-1, respectively, thus both contribute to impaired eNOS phosphorylation.

Rats in which preeclampsia is induced by the viral administration of human sFlt-1, sensitivity to AngII is reestablished [19]. In another model of (mild) preeclampsia, induced by a systemic deficiency in catechol-O-methyl transferase (COMT), mice also displayed AngII hypersensitivity [37] and an increase ( $\sim 20 \%$ at Day 17 of gestation) in sFlt-1 concentration [38]. COMT is the enzyme that catalyzes the conversion of 2-hydroxyestradiol into 2-methoxyestradiol (2-ME). Mechanistically, 2-ME induces proliferating peroxisome-activated receptor gamma, a transcription factor that represses ATR1 [37, 38]. COMT-deficient mice logically exhibit an increased sensitivity to AngII. In both models of preeclampsia-COMT knockout and human sFlt-1 overexpression-SC reduces this vascular hypersensitivity to vasoconstrictors $[19,39]$.

How exactly NO modulates the endothelial sensitivity to AngII is not fully elucidated. NO decreases the activity of ACE and the conversion from AngI to AngII [40] and also acts as a 


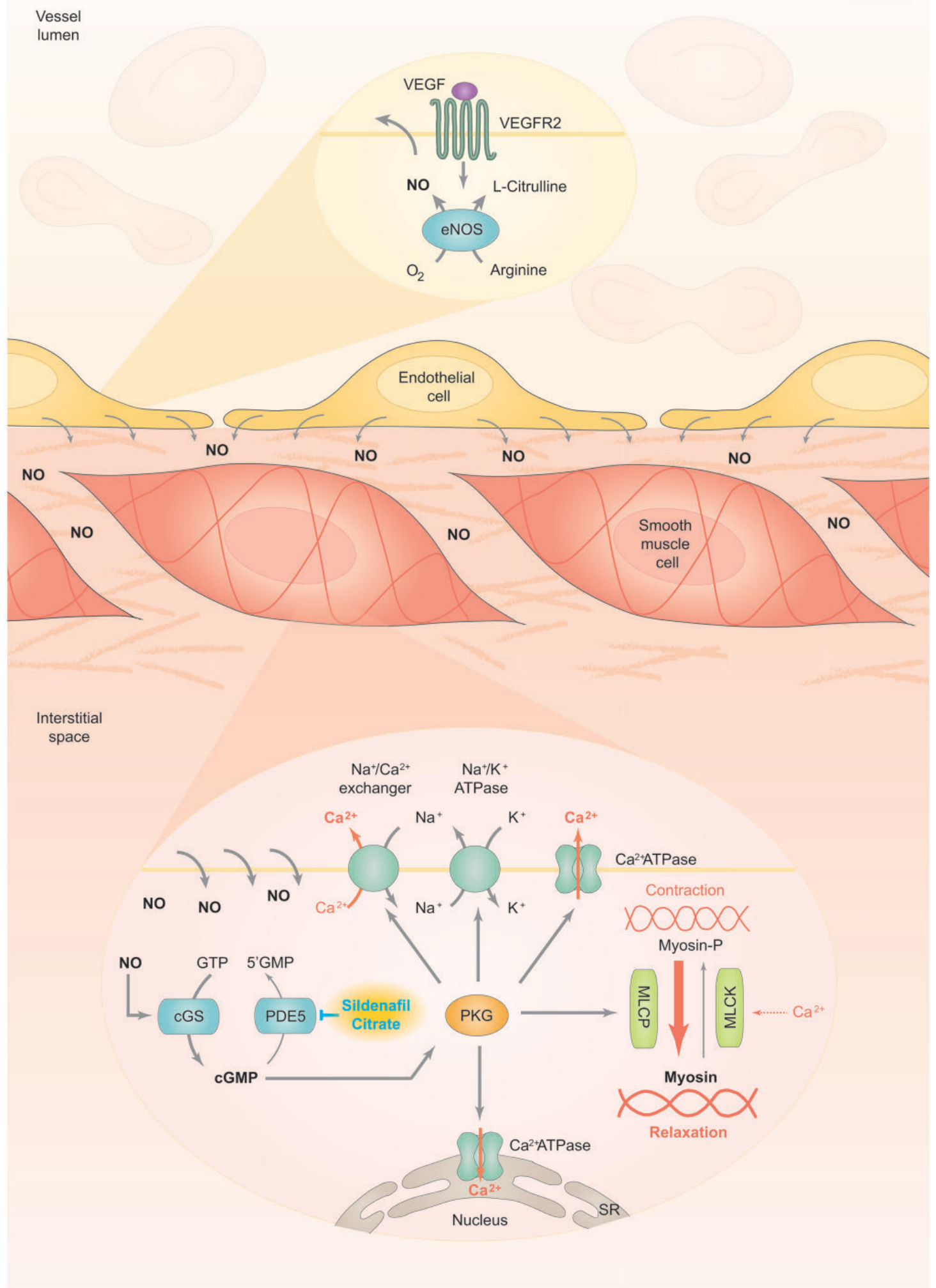

FIGURE 1: Mechanisms of vessel relaxation and effect of SC. Relaxation of the vasculature is dependent on the cross-talk between endothelial and smooth muscle cells. The NO is produced by the eNOS and can be induced by various stimuli, including VEGF through VEGFR-2. The gas freely crosses the membrane of the smooth muscle cell to activate cGMP synthase (cGS). The second messenger then stimulates phosphokinase G (PKG), which leads to the dephosphorylation of myosin through direct activation of myosin light chain phosphatase (MLCP) or inhibition of myosin light chain kinase (MLCK) by a reduction the cytoplasmic concentration of calcium $\left(\mathrm{Ca}^{2+}\right)$. This last phenomenon relies on PKG-dependent stimulation of the membranous and sarcoplasmic $\mathrm{Ca}^{2+}$ adenosine triphosphatase and the $\mathrm{Na}^{+}-\mathrm{Ca}^{2+}$ exchanger, which pump out the divalent cation from the cytoplasm. By inhibiting PDE5, SC prevents the degradation of cGMP in $5^{\prime}$-GMP, thus sustaining the cellular stock of cGMP and the relaxation state [20,21]. GTP, guanosine-5'-triphosphate; SR, sarcoplasmic reticulum. 


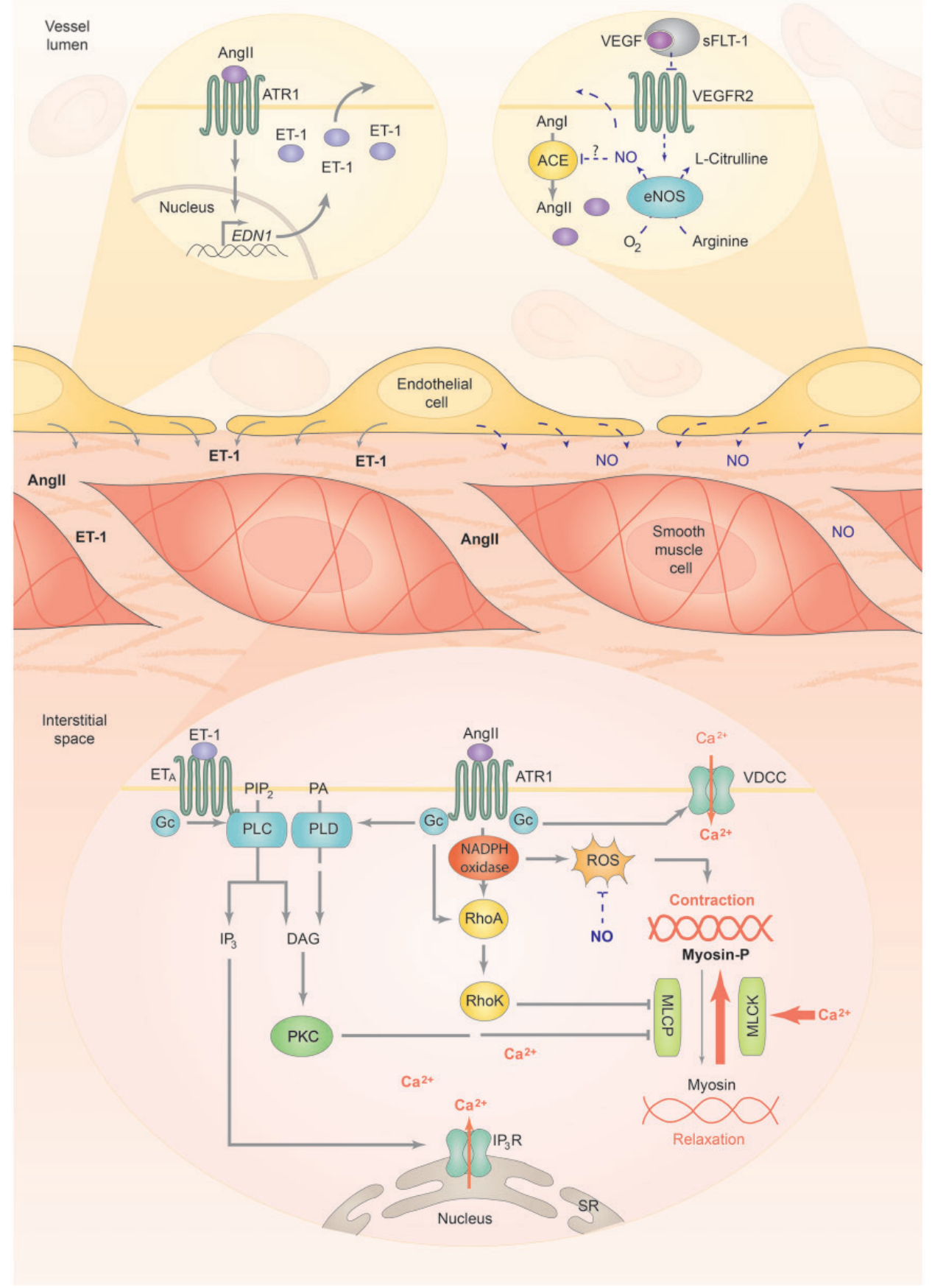

FIGURE 2: Synergy of AngII and endothelin-1 (ET-1) in vascular contraction and their pathologic effect in preeclampsia. The AngII receptor ATR1 is located on both the endothelial and smooth muscle cell membranes. Among its effects, AngII induces the production of ET-1 by the endothelial cells through its receptor ATR1; the two peptidic hormones then participate together in the contraction of smooth muscle cells.

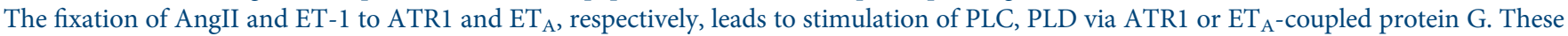
two enzymes cut membranous phospholipids. The PLC converts phosphatidylinositol 4,5-bisphosphate into inositol triphosphate (IP ${ }_{3}$ ), which opens a specific calcium channel on the sarcoplasmic reticulum $\left(\mathrm{IP}_{3} \mathrm{R}\right)$, increasing cytoplasmic $\mathrm{Ca}^{2+}$ concentration and promoting myosin fibre contraction, thence into diacylglycerol (DAG), which activates phosphokinase C (PKC), which subsequently induces myosin light-chain phosphatase (MLCP) inactivation. The PLD acts in a similar way by indirectly converting the phosphatidic acid into DAG. These two mechanisms are Gq-dependently strengthened by the opening of the voltage-dependent L-type $\mathrm{Ca}^{2+}$ channel, with the entrance of $\mathrm{Ca}^{2+}$ from the extracellular space into the cytoplasmic compartment, and activation of the Rho signalling pathway, inhibiting MLCP. Altogether these processes contribute to smooth muscle cell contraction [20,26]. In pregnancy, circulating levels of both AngII and NO are elevated, the combination resulting in a relative resistance to AngII-dependent contraction. However, in preeclampsia, NO contents decrease secondary to the placental secretion of sFlt-1. The soluble receptor traps VEGF, thus preventing endothelial NO production and subsequently leading to more cleavage by the ACE of AngI into AngII, as NO may act as an inhibitor of the enzyme. AngII can also activate Rho member A (RhoA) by nicotinamide adenine dinucleotide phosphate (NADPH) oxidase, which generates reactive oxygen species (ROS), thus sustaining the state of contraction. The NO deprivation amplifies this last phenomenon as the gas can act as a scavenger for ROS [27]. 
scavenger of oxidants, which are required for AngII-induced hypertension [41].

\section{RELEVANCE OF SC FOR PREECLAMPSIA:} SOME PROMISING PRECLINICAL STUDIES

At present, no specific drug targets sFlt-1, which is why a drug targeting the downstream effects in the preeclamptic maternal endothelium is promising. SC acts through a highly specific inhibition of PDE5, the enzyme that consumes cGMP by converting it into guanosine- $5^{\prime}$-triphosphate. cGMP is the first of the second messengers in the NO pathway [23] (Figure 1). The drug was developed in the 1990s as a vasodilatory agent to improve heart failure, but in dose-response Phase I studies it was shown to potentialize the effects of glyceryl trinitrate and to induce penile erection. Eventually erectile dysfunction became the primary indication of SC, with pulmonary arterial hypertension also an indication, but to a much lesser extent (the alveolar endothelium is dependent on NO to become distended in response to inspiration) [23]. Although PDE5 is expressed in almost all tissues, SC selectively acts on only some vascular beds, resulting in a modest reduction in blood pressure in humans, a desirable profile in pregnancy, as a sudden systemic blood pressure drop is deleterious for the foetus [23]. PDE5 inhibitors are thus an interesting alternative to previous strategies that aimed to manipulate the NO pathway in preeclamptic women. NO donors such as glyceryl trinitrate or isosorbide dinitrate or NO precursors such as L-arginine have not proven to be entirely satisfactory [22]. PDE inhibitors were tested ex vivo in myometrial biopsies and induced vasodilation in arteries dissected out from preeclamptic subjects, without any effect on placental or omental arteries [25, 42]. In a rat model of preeclampsia induced by suramin (a potent antiangiogenic drug), SC rescued the inhibitory effect on the relaxation induced by nitro-L-arginine methyl ester (L-NAME; a NOS inhibitor) or 1H-[1,2,4] oxadiazolo[4,3a]quinoxalin-1-one (a guanylyl cyclase inhibitor, the enzyme that produces cGMP) on thoracic aorta explants [43]. This efficacy was confirmed ex vivo on umbilical arteries isolated from the placenta of preeclamptic pregnancies [44]. In several studies in pregnant rats exposed to L-NAME, the effect of SC on blood pressure control, foetal weight and survival, microalbuminuria (along with a lower quantity of urinary messenger RNA of podocin and nephrin, used here as markers of glomerular injury) has been demonstrated [36-40]. In this model, the pups had impaired learning, also restored by SC, suggesting a protective effect not only on the maternal endothelium but also in the offspring [45]. Furthermore, mice carrying a heterozygous deletion of the eNOS gene, affected by a mild hypertensive phenotype, displayed better arterial pressure control and foetal outcome under SC [46]. SC has also been reported to be effective in COMT-deficient mice (a model where preeclampsia is mild but not directly caused by inhibition of NO). It had no impact on blood pressure-and even increased albuminuria-but it improved foetal growth by $20 \%$, most probably by reducing placental arterial resistance [37].

The efficacy of SC might actually go beyond NO metabolism. When given in nonpregnant COMT-deficient mice, SC decreases the serum accumulation of fatty acids and its oxidation intermediates, restoring circulating levels of kynurenine, a precursor of nicotinamide adenine dinucleotide, a ratelimiting compound of oxidative phosphorylation [47]. These results are relevant because mitochondrial dysfunction (on oxidative phosphorylation) is evident in the placenta of preeclamptic women [48]. SC was also found to be of benefit in another model of preeclampsia induced by the clamping of uterine arteries, where the placenta is hypoxic and sFlt- 1 is high; of note, the drug had little effect on blood pressure in control rats [49]. Gillis et al. [50], however, described the real antihypertensive effect of SC in Dahl salt-sensitive rats, along with decreased proteinuria, decreased uterine artery resistance and a better outcome in pups (increased foetal survival, size and weight).

Timely mechanistic data were provided by the work of Burke et al. [19], where SC attenuated sFlt-1-induced preeclampsia and restored a normally low sensitivity to AngII in pregnant mice. By blunting VEGF-driven phosphorylation (hence activity) of eNOS, sFlt-1 increases oxidative stress because NO would normally act as a scavenger of oxidants. In preeclamptic vessels, AngII sensitivity was increased by L-NAME and reversed by SC, confirming the pivotal role played here by NO. Together, these are encouraging data for measurement of the clinical efficacy of SC in humans.

\section{THE USE OF SC AT THE ONSET OF PREECLAMPSIA: CLINICAL STUDIES}

To begin with, a meta-analysis pooled the results of preclinical and clinical studies, pointing out some pitfalls in the translation of SC use from rodents to humans: preclinical studies used higher doses (from 4 to $100 \mathrm{mg} / \mathrm{kg} / \mathrm{day}$, so at least four times the dose used in clinical trials) and at an earlier stage of pregnancy, when placentation is still ongoing [51]. It should be stressed that prolongation of pregnancy is a major aim since it decreases both morbidity at early and late terms of gestation $[52,53]$ and cost [54]. However, this is a debatable criterion for outcome since it is dependent on the decision of the investigators to move delivery forward. The ideal (but more complex) criterion would be the preeclampsia-free duration of pregnancy in the case of its introduction before the onset of clinical manifestations. Other PDE5 inhibitors could also be of interest. Vardenafil, for instance, showed an even better vasodilatory effect on umbilical arteries from preeclamptic pregnancies and an increase in the secretion of PlGF by endothelial cells $[44,55]$. Tadalafil might be advantageous, as it appears not to cross the placental barrier [56] and was recently found to be safe in a small safety trial (although only eight women were included) [57].

In 2003, years before any in vitro or in vivo evidence, Downing et al. [58] hypothesized that PDE5 inhibitors would be beneficial in preeclampsia. This was based on the idea that accumulation of cGMP would increase vasodilation and NO production would prevent oxidative stress. The first doubleblind, placebo-controlled clinical trial of the use of SC in preeclampsia was published 6 years later. Patients were included if they had early-onset preeclampsia (defined here as hypertension plus proteinuria $>500 \mathrm{mg} /$ day between 24 and 34 weeks of gestation). The primary outcome was the prolongation of 
pregnancy. Gestational age at randomization was $31+4$ weeks in the SC group and $29+0$ in the placebo group. The study found no significant difference between groups. Nonetheless, the size of groups (20 subjects each) was probably too small to draw a firm conclusion, with SC, whose half-life is $<4 \mathrm{~h}$, given only once a day at a very low dose compared with that used in preclinical studies $(20 \mathrm{mg} /$ day, with a progressive increase up to $80 \mathrm{mg}$ if the drug was well tolerated) [59]. Importantly, in this study, where sildenafil use never exceeded 15 days and where mean gestational age at inclusion was $\sim 30$ weeks, there were no safety issues regarding the neonates. In particular, surfactantdeficient lung disease and mortality were comparable between groups. This trial revealed a good SC tolerance profile during preeclampsia and a significant antihypertensive effect: mean diastolic blood pressure decreased from $88 \mathrm{mmHg}$ at randomization to 80 at delivery, while it rose from 90 to 96 in the placebo group [59].

The same group performed a parallel study in which they used pressure myography to analyze the relaxation of the arteries extracted from the umbilical cord and the omentum of the study subjects. They found no difference between groups, showing that the drug had no effect on ex vivo samples [60].

Trapani et al. [61] recently published similar results in another placebo-controlled trial with a larger cohort of subjects. Inclusion criteria were similar (early-onset preeclampsia), but with a higher dose and a better distribution of SC: $50 \mathrm{mg}$ every $8 \mathrm{~h}$. While in the first study most women were nulliparous, the population of this trial was more heterogeneous, with half being multiparous. Mean gestational age was also $\sim 30$ weeks. A 4-day increase in the duration of pregnancy was observed in the treated group, as well as a significant decrease in mean arterial pressure (from $116.4 \pm 5.1$ to $100.3 \pm 5.6 \mathrm{mmHg}$ at $24 \mathrm{~h}$ ); a reduced pulsatile index in the uterine and umbilical arteries was also noted (of a modest magnitude compared with the numbers typically observed in healthy pregnancies) without affecting the velocimetric profile of the foetal middle cerebral artery. Outcomes for the baby after delivery were similar to the placebo group, arguing in favour of a selective maternal effect [61, 62]. Respiratory distress syndrome in particular was equivalent between groups, as was death.

\section{Disturbing results from the STRIDER trial}

The STRIDER trial (Sildenafil TheRapy in dismal prognosis early onset fetal growth restriction) was meant to present further data on the tolerance and relevance of the prolonged use of sildenafil in early pregnancy (between 22 and 30 weeks of gestation) complicated by IUGR [63]. The UK arm of the trial, conducted in 19 foetal medical units, was published in February 2018 [64]. It failed to demonstrate a beneficial effect of lowdose SC (25 mg three times per day) to prolong pregnancy: time to delivery was 17 days in women exposed to SC versus 18 days in the placebo group. The safety profile of SC was good overall, and perinatal mortality and morbidity were statistically comparable (including the use of surfactant in neonates). However, on 24 July 2018, the lead investigator of the Dutch arm, Dr Wessel Ganzevoort, gave a public interview to de Volskrant, a Dutch daily morning newspaper, in which he reported that SC was associated with an increased risk of pulmonary hypertension in newborn babies (17 cases versus 3 in the placebo group) and increased mortality (19 versus 8 , of which 11 versus 0 had pulmonary issues). This information led to the suspension of the Canadian arm of the trial [65] and was widely reported in the international nonspecialist press.

\section{CONCLUSION}

Preeclampsia is a frequent, potentially fatal syndrome and has long-term consequences for both the mother and her child. Until recently, SC was found to have a satisfactory safety and efficacy profile as an antihypertensive agent in preeclamptic women. However, the Dutch arm of the STRIDER trial, where SC was given early and for up to 4 weeks, rang an alarming warning bell regarding the potential increase in the risk of pulmonary hypertension in neonates, which might be fatal even though a causal link to SC has not yet been proven. Any enthusiasm regarding SC must be tempered by these findings and we must assume a degree of pessimism regarding the future of SC as a drug that improves IUGR and its use before delivery. Whether tadalafil, which does not cross the placental barrier, has similar antihypertensive efficacy and safety in preeclamptic women is uncertain at this time. Very recently, a Phase 2 trial studying the use of tadalafil in IUGR in Japan (UMIN000023778) was stopped prematurely due to the results from the STRIDER trial, but its partial results may give some answers regarding the safety of this other PDE5 inhibitor. However, in our opinion and looking at it from a pathophysiological angle, postpartum use of SC as an antihypertensive drug deserves further investigation.

\section{CONFLICT OF INTEREST STATEMENT}

None declared.

\section{REFERENCES}

1. Tranquilli AL, Brown MA, Zeeman GG et al. The definition of severe and early-onset preeclampsia. Statements from the International Society for the Study of Hypertension in Pregnancy (ISSHP). Pregnancy Hypertens 2013; 3: 44-47

2. Sircar M, Thadhani R, Karumanchi SA. Pathogenesis of preeclampsia. Curr Opin Nephrol Hypertens 2015; 24: 131-138

3. Duley L. The global impact of pre-eclampsia and eclampsia. Semin Perinatol 2009; 33: 130-137

4. Lisonkova S, Joseph KS. Incidence of preeclampsia: risk factors and outcomes associated with early- versus late-onset disease. Am J Obstet Gynecol 2013; 209: 544.e1-544.e12

5. Breetveld NM, Ghossein-Doha C, van Neer J et al. Decreased endothelial function and increased subclinical heart failure in women, many years after pre-eclampsia. Ultrasound Obstet Gynecol 2018; 52: 196-204

6. Ahmed R, Dunford J, Mehran R et al. Pre-eclampsia and future cardiovascular risk among women: a review. J Am Coll Cardiol 2014; 63: 1815-1822

7. Kattah AG, Scantlebury DC, Agarwal S et al. Preeclampsia and ESRD: the role of shared risk factors. Am J Kidney Dis 2017; 69: 498-505

8. Vikse BE, Irgens LM, Leivestad T et al. Preeclampsia and the risk of endstage renal disease. $N$ Engl J Med 2008; 359: 800-809

9. Wang IK, Muo CH, Chang YC et al. Association between hypertensive disorders during pregnancy and end-stage renal disease: a population-based study. CMAJ 2013; 185: 207-213

10. Alsnes IV, Vatten LJ, Fraser A et al. Hypertension in pregnancy and offspring cardiovascular risk in young adulthood: prospective and sibling 
studies in the HUNT Study (Nord-Trøndelag Health Study) in Norway. Hypertension 2017; 69: 591-598

11. Staff AC, Braekke K, Harsem NK et al. Circulating concentrations of sFlt1 (soluble fms-like tyrosine kinase 1) in fetal and maternal serum during preeclampsia. Eur J Obstet Gynecol Reprod Biol 2005; 122: 33-39

12. Dang F, Croy BA, Stroman PW et al. Impacts of preeclampsia on the brain of the offspring. Rev Bras Ginecol Obstet 2016; 38: 416-422

13. Kajantie E, Eriksson JG, Osmond C et al. Pre-eclampsia is associated with increased risk of stroke in the adult offspring: the Helsinki birth cohort study. Stroke 2009; 40: 1176-1180

14. Wu FTH, Stefanini MO, Mac Gabhann F et al. A systems biology perspective on sVEGFR1: its biological function, pathogenic role and therapeutic use. J Cell Mol Med 2010; 14: 528-552

15. Maynard SE, Min JY, Merchan J et al. Excess placental soluble fms-like tyrosine kinase 1 (sFlt1) may contribute to endothelial dysfunction, hypertension, and proteinuria in preeclampsia. J Clin Invest 2003; 111: 649-658

16. Kabbinavar F, Hurwitz HI, Fehrenbacher L et al. Phase II, randomized trial comparing bevacizumab plus fluorouracil (FU)/leucovorin (LV) with FU/LV alone in patients with metastatic colorectal cancer. J Clin Oncol 2003; 21: 60-65

17. Thadhani R, Hagmann H, Schaarschmidt W et al. Removal of soluble Fmslike tyrosine kinase-1 by dextran sulfate apheresis in preeclampsia. J Am Soc Nephrol 2016; 27: 903-913

18. Haddad B. LDL-apheresis to decrease sFlt-1 during early severe preeclampsia: report of two cases from a discontinued Phase II trial. Eur J Obstet Gynecol Reprod Biol 2018; 231: 70-74

19. Burke SD, Zsengellér ZK, Khankin EV et al. Soluble fms-like tyrosine kinase 1 promotes angiotensin II sensitivity in preeclampsia. J Clin Invest 2016; 126: 2561-2574

20. Yan C, Kim D, Aizawa T et al. Functional interplay between angiotensin II and nitric oxide: cyclic GMP as a key mediator. Arterioscler Thromb Vasc Biol 2003; 23: 26-36

21. Feliers $\mathrm{D}$, Chen $\mathrm{X}$, Akis $\mathrm{N}$ et al. VEGF regulation of endothelial nitric oxide synthase in glomerular endothelial cells. Kidney Int 2005; 68: 1648-1659

22. Johal T, Lees CC, Everett TR et al. The nitric oxide pathway and possible therapeutic options in pre-eclampsia. Br J Clin Pharmacol 2014; 78: 244-257

23. Ghofrani HA, Osterloh IH, Grimminger F. Sildenafil: from angina to erectile dysfunction to pulmonary hypertension and beyond. Nat Rev Drug Discov 2006; 5: 689-702

24. Chivers ML, Rosen RC. Phosphodiesterase type 5 inhibitors and female sexual response: faulty protocols or paradigms? J Sex Med 2010; 7: 858-872

25. Wareing M, Myers JE, O'Hara $M$ et al. Effects of a phosphodiesterase- 5 (PDE5) inhibitor on endothelium-dependent relaxation of myometrial small arteries. Am J Obstet Gynecol 2004; 190: 1283-1290

26. Bakrania B, Duncan J, Warrington J et al. The endothelin type A receptor as a potential therapeutic target in preeclampsia. Int J Mol Sci 2017; 18: pii: E522

27. Jin L, Ying Z, Hilgers RHP et al. Increased RhoA/Rho-kinase signaling mediates spontaneous tone in aorta from angiotensin II-induced hypertensive rats. J Pharmacol Exp Ther 2006; 318: 288-295

28. Takimoto E, Ishida J, Sugiyama F et al. Hypertension induced in pregnant mice by placental renin and maternal angiotensinogen. Science 1996; 274: 995-998

29. Cunningham MW, Williams JM, Amaral L et al. Agonistic autoantibodies to the angiotensin II type 1 receptor enhance angiotensin II-induced renal vascular sensitivity and reduce renal function during pregnancy. Hypertension 2016; 68: 1308-1313

30. Verdonk K, Visser W, Van Den Meiracker AH et al. The reninangiotensin-aldosterone system in pre-eclampsia: the delicate balance between good and bad. Clin Sci 2014; 126: 537-544

31. Gant NF, Daley GL, Chand S et al. A study of angiotensin II pressor response throughout primigravid pregnancy. J Clin Invest 1973; 52: 2682-2689

32. Stanhewicz AE, Jandu S, Santhanam L et al. Increased angiotensin II sensitivity contributes to microvascular dysfunction in women who have had preeclampsia. Hypertension 2017; 70: 382-389

33. van der Graaf AM, Toering TJ, van der Wiel MWK et al. Angiotensin II responsiveness after preeclampsia: translational data from an experimental rat model and early-onset human preeclampsia. J Hypertens 2017; 35: $2468-2478$
34. Barr M. Teratogen update: angiotensin-converting enzyme inhibitors. Teratology 1994; 50: 399-409

35. Ueki N, Takeda S, Koya D et al. The relevance of the renin-angiotensin system in the development of drugs to combat preeclampsia. Int J Endocrinol 2015; 2015: 572713

36. Venkatesha S, Toporsian M, Lam C et al. Soluble endoglin contributes to the pathogenesis of preeclampsia. Nat Med 2006; 12: 642-649

37. Ueki $\mathrm{N}$, Kanasaki $\mathrm{K}$, Kanasaki $\mathrm{M}$ et al. Catechol-O-methyltransferase deficiency leads to hypersensitivity of the pressor response against angiotensin II. Hypertension 2017; 69: 1156-1164

38. Kanasaki K, Palmsten K, Sugimoto $\mathrm{H}$ et al. Deficiency in catechol-O-methyltransferase and 2-methoxyoestradiol is associated with pre-eclampsia. Nature 2008; 453: 1117-1121

39. Stanley JL, Andersson IJ, Poudel R et al. Sildenafil citrate rescues fetal growth in the catechol-O-methyl transferase knockout mouse model. Hypertension 2012; 59: 1021-1028

40. Ackermann A, Fernández-Alfonso MS, Sánchez de Rojas $\mathrm{R}$ et al. Modulation of angiotensin-converting enzyme by nitric oxide. $\mathrm{Br} J$ Pharmacol 1998; 124: 291-298

41. Guo W, Adachi T, Matsui R et al. Quantitative assessment of tyrosine nitration of manganese superoxide dismutase in angiotensin II-infused rat kidney. Am J Physiol Heart Circ Physiol 2003; 285: H1396-H1403

42. Wareing M, Myers JE, O'Hara M et al. Phosphodiesterase-5 inhibitors and omental and placental small artery function in normal pregnancy and preeclampsia. Eur J Obstet Gynecol Reprod Biol 2006; 127: 41-49

43. Turgut NH, Temiz TK, Bagcivan I et al. The effect of sildenafil on the altered thoracic aorta smooth muscle responses in rat pre-eclampsia model. Eur J Pharmacol 2008; 589: 180-187

44. Karasu E, Kayacan N, Sadan G et al. Different effects of different phosphodiesterase type-5 inhibitors in pre-eclampsia. Pregnancy Hypertens 2011; 1: 231-237

45. Cauli O, Herraiz S, Pellicer B et al. Treatment with sildenafil prevents impairment of learning in rats born to pre-eclamptic mothers. Neuroscience 2010; 171: 506-512

46. Roberts RP, Refuerzo JS, Ferrari F et al. Sildenafil treatment in a nonsevere hypertensive murine model lowers blood pressure without reducing fetal growth. Am J Obstet Gynecol 2016; 215: 386.e1-388

47. Stanley JL, Sulek K, Andersson IJ et al. Sildenafil therapy normalizes the aberrant metabolomic profile in the $\mathrm{Comt}^{-1-}$ mouse model of preeclampsia/ fetal growth restriction. Sci Rep 2015; 5: 18241

48. Zsengellér ZK, Rajakumar A, Hunter JT et al. Trophoblast mitochondrial function is impaired in preeclampsia and correlates negatively with the expression of soluble fms-like tyrosine kinase 1. Pregnancy Hypertens 2016; 6: 313-319

49. George EM, Palei AC, Dent EA et al. Sildenafil attenuates placental ischemia-induced hypertension. Am J Physiol Regul Integr Comp Physiol 2013; 305: R397-R403

50. Gillis EE, Mooney JN, Garrett MR et al. Sildenafil treatment ameliorates the maternal syndrome of preeclampsia and rescues fetal growth in the Dahl salt-sensitive rat. Hypertension 2016; 67: 647-653

51. Paauw ND, Terstappen F, Ganzevoort W et al. Sildenafil during pregnancy: a preclinical meta-analysis on fetal growth and maternal blood pressure. Hypertension 2017; 70: 998-1006

52. Belghiti J, Kayem G, Tsatsaris V et al. Benefits and risks of expectant management of severe preeclampsia at less than 26 weeks gestation: the impact of gestational age and severe fetal growth restriction. Am J Obstet Gynecol 2011; 205: 465e1-465e6

53. Parikh LI, Reddy UM, Männistö T et al. Neonatal outcomes in early term birth. Am J Obstet Gynecol 2014; 211: 265.e1-265.e11.

54. Hall ES, Greenberg JM. Estimating community-level costs of preterm birth. Public Health 2016; 141: 222-228

55. Kakigano A, Tomimatsu T, Mimura K et al. Drug repositioning for preeclampsia therapeutics by in vitro screening: phosphodiesterase- 5 inhibitor vardenafil restores endothelial dysfunction via induction of placental growth factor. Reprod Sci 2015; 22: 1272-1280

56. Walton RB, Reed LC, Estrada SM et al. Evaluation of sildenafil and tadalafil for reversing constriction of fetal arteries in a human placenta perfusion model. Hypertension 2018; 72: 167-176 
57. Furuhashi FH, Tanaka H, Kaneda MK et al. Safety trial of tadalafil administered for the treatment of preeclampsia. J Matern Fetal Neonatal Med 2018; 1-4. doi:10.1080/14767058.2018.1487946

58. Downing JW, Ramasubramanian R, Johnson RF et al. Hypothesis: selective phosphodiesterase-5 inhibition improves outcome in preeclampsia. Med Hypotheses 2004; 63: 1057-1064

59. Samangaya RA, Mires G, Shennan A et al. A randomised, double-blinded, placebo-controlled study of the phosphodiesterase type 5 inhibitor sildenafil for the treatment of preeclampsia. Hypertens Pregnancy 2009; 28: 369-382

60. Samangaya RA, Wareing M, Skillern L et al. Phosphodiesterase inhibitor effect on small artery function in preeclampsia. Hypertens Pregnancy 2011; 30: $144-152$

61. Trapani A, Gonçalves LF, Trapani TF et al. Perinatal and hemodynamic evaluation of sildenafil citrate for preeclampsia treatment: a randomized controlled trial. Obstet Gynecol 2016; 128: 253-259
62. Arduini D, Rizzo G, Normal values of pulsatility index from fetal vessels: a cross-sectional study on 1556 healthy fetuses. J Perinat Med 1990; 18: $165-172$

63. Ganzevoort W, Alfirevic Z, von Dadelszen P et al. STRIDER: sildenafil therapy in dismal prognosis early-onset intrauterine growth restrictiona protocol for a systematic review with individual participant data and aggregate data meta-analysis and trial sequential analysis. Syst Rev 2014; $3: 23$

64. Sharp A, Cornforth C, Jackson R et al. Maternal sildenafil for severe fetal growth restriction (STRIDER): a multicentre, randomised, placebocontrolled, double-blind trial. Lancet Child Adolesc Health 2018; 2: 93-102

65. Hawkes $\mathrm{N}$. Trial of Viagra for fetal growth restriction is halted after baby deaths. BMJ 2018; 362: k3247 